\title{
Divergent functional traits in three sympatric Arctic charr Salvelinus alpinus morphs are not coupled with the age of the lineage divergence
}

\author{
Carolyn Bryce $\cdot$ Alicia Fraser $\cdot$ Rune Knudsen $\cdot$ Ron Greer $\cdot$ Colin Adams
}

Received: 5 March 2016/Revised: 21 August 2016/Accepted: 22 August 2016/Published online: 24 October 2016

(C) The Author(s) 2016. This article is published with open access at Springerlink.com

\begin{abstract}
Three genetically discrete morphs of Arctic charr in Loch Rannoch, Scotland originated from a recent divergence within the lake (in situ) (piscivore and benthivore morphs) and from secondary contact of two older lineages (ex situ; a planktivore-piscivore/ benthivore divergence). To test if the expression of traits with strong functional roles was linked to the age of the divergence, fin and gill anatomy, and dentition were quantified and compared across morphs. Five additional working hypotheses suggesting a rank order of trait expression amongst morphs were also tested. The planktivorous morph had more rays in the dorsal and pectoral fins, longer gill rakers (but not more) as well as a smaller gill cavity than the other two morphs.
\end{abstract}

Guest editors: M. Power, R. Knudsen, C. Adams, M. J. Hansen, J. B. Dempson, M. Jobling \& M. Ferguson / Advances in Charr Ecology and Evolution

C. Bryce - A. Fraser · C. Adams $(\bowtie)$

The Scottish Centre for Ecology \& the Natural

Environment, Institute of Biodiversity, Animal Health and Comparative Medicine, CMVLS, University of Glasgow, Rowardennan, Glasgow G63 0AW, UK

e-mail: colin.adams@glasgow.ac.uk

R. Knudsen - C. Adams

Department of Arctic and Marine Biology, UiT The

Arctic University of Norway, 9037 Tromsö, Norway

R. Greer

The Armoury House, Blair Atholl, Perthshire PH18 5SG, UK
The piscivorous morph had more palatine teeth and longer teeth on the mandible, pre-maxillary and glossohyal bones, and a larger buccal cavity. These differences indicate a differential response to selection in these functional anatomical features most likely related to morph foraging specialisms. Notably, between-morph divergences in the expression of these traits were not simply linked to the length of divergence between morphs and have arisen equally quickly in the recent (in situ) divergence as they have in older, ex situ divergences.

Keywords Evolution - Trophic specialism . Ecomorphs $\cdot$ Phenotypic variation

\section{Introduction}

The extent to which species exhibit intra-specific structuring in their genotype and expressed phenotype is becoming increasingly apparent (see e.g. Kang et al., 2013; Swislocka et al., 2013). In some systems, it is clear that such structuring has arisen quickly and relatively recently (Gislason et al., 1999; Garduño-Paz et al., 2012). This is particularly true for fishes occupying freshwater lakes that have been recently glaciated (see Skulason et al., 1999 for a general overview; for contrasting exemplars, see Ferguson, 1989; Svanbäck \& Eklöv, 2004; Verspoor et al., 2005; Hendry et al., 2009; Muir et al., 2015). 
Where such patterning has been reported, it is often inferred, although difficult to empirically demonstrate, that this is the result of a local adaptive response to local selection pressures which are either contemporary or the result of a legacy of historical selection (Bush \& Adams, 2007; Garant et al., 2007; Woods et al., 2012). Patterns exhibited by such structuring are highly informative in that they provide insights into the evolutionary processes that have ultimately shaped phenotypic and genetic configurations in nature. Such insights are even more valuable where structuring has developed in a single population and has manifested as distinct intra-specific groups occupying the same ecosystem. In such systems, the observed evolutionary divergences are maintained and driven in populations of individuals exposed to broadly the same environmental conditions (temperature, latitude, foraging opportunities, biotic, competition, etc.).

Several species of freshwater fishes inhabiting recently glaciated lakes show clear and distinct structuring of phenotype in sympatry. Phenotypic structuring is often also reflected in genotype differences. See as exemplars, European whitefish, Coregonus lavaretus (L. 1758) (Kahilainen \& Ostbye, 2006; Siwertsson et al., 2013), pygmy whitefish, Prosopium coulterii (Eigenmann \& Eigenmann 1892) (Gowell et al., 2012), North American lake whitefish, Coregonus clupeaformis, Lacepede 1803, (Gagnaire et al., 2013), both three-spined stickleback, Gasterosteus aculeatus L. 1758, (Lavin \& McPhail, 1986; Defaveri et al., 2013), and nine-spined stickleback, Pungitius pungitius (L. 1758) (Ishikawa et al., 2013) and European perch, Perca fluviatilis L. 1758, (Svanbäck \& Persson, 2004).

Where this occurs, there is almost always a strong ecological divergence between the alternative groups, most often manifested as alternative foraging specialisms. This is usually accompanied by some morphological adaptations related to the foraging specialisation. Where at least the ecological and morphological divergences amongst groups are clear and discrete, the alternative phenotypes are often termed morphs or ecomorphs.

Prominent amongst the species known to exhibit multiple morphs living in sympatry is the Arctic charr, Salvelinus alpinus (L. 1758) (Danzmann et al., 1991; Fraser et al., 1998; Jonsson \& Jonsson, 2001; Klemetsen et al., 2003; Knudsen et al., 2007). In some lakes where such polymorphisms have been described, the morphs have arisen in sympatry (Gislason et al., 1999; Verspoor et al., 2010; Garduño-Paz et al., 2012), but this is not always be the case (see Garduño-Paz et al, 2012). There is significant evidence from Arctic charr of parallel, in situ divergences resulting in the emergence of similar ecological specialists occurring in different lake systems across the range of the species (Jonsson \& Jonsson, 2001; Alekseyev et al., 2002; Adams et al., 2008).

There is a general assumption that phenotypic differences exhibited by sympatric morphs are adaptive, driven by selection forces and are thus strongly functional. The vast majority of analyses of phenotype in Arctic charr have focused on external morphology (Adams \& Huntingford, 2002a), but there are a number of other elements of fish anatomy which have important ecological functions which are poorly understood. Gill raker length and spacing are frequently correlated with foraging specialisms in fishes. Fish exhibiting closely spaced and longer rakers often show evidence of foraging on smaller prey than conspecifics, or closely related species, with the alternative gill raker format (for a thorough review see Gerking, 1994). Gill raker number in Arctic charr has been shown to vary between morphs (Frost, 1965), but the evidence of the literature is that they do not vary as obviously as they do in ecomorphs of related fish groups, for example, amongst the coregonidae (Kahilainen et al., 2011). The dentition of closely related fish species has been examined in a number of groups, most notably the African cichlids, where there is strong evidence of foraging specialisms being correlated with variation in dentition (Burress, 2015). Despite the obvious role of teeth in foraging, variation in dentition has not been systematically examined in salmonid foraging specialists. Bony rays provide fins with the rigidity needed to convert muscular movement at their base into fin movement in teleost fishes. Thus, in a general sense, fins rays are important for fin function. Despite this, there is little known about the effect of variation in fin ray form or number on the subtleties of ultimate fin function (Taft \& Taft, 2012).

Loch Rannoch, Scotland supports Arctic charr which comprises three distinct forms that differ in ecology, morphology, behaviour, life history and parasite loading (Dorucu et al., 1995; Mikheev et al., 1996; Adams et al., 1998; Adams \& Huntingford, 2004). There are also clear genetic differences 
amongst them (Verspoor et al., 2010). This polymorphism represents one of the best-studied sympatric morph systems of Arctic charr (Klemetsen, 2010), and has been described fully elsewhere; thus only a brief summary is presented here.

The planktivorous morph is a plankton-feeding specialist which exhibits a fusiform body shape with a relatively small delicate head and relatively large eyes. This form inhabits the limnetic zone of the lake, foraging on the smallest prey of the three forms, zooplankton (Adams et al., 1998; Fraser et al., 2008).

The benthivorous morph displays a relatively deeper, more robust head and jaw structure. It feeds on larger benthic-living crustacea and insect larvae, and nymphs in the littoral zone of the lake (Adams et al., 1998) and thus consumes prey that is intermediate in size to that of the other two morphs (Fraser et al., 2008).

The piscivorous morph has a very robust head and large gape, and feeds on fish at a relatively small size. It is mostly found in the profundal zone of the lake and feeds on the largest of the prey types of the three morphs (Adams et al., 1998; Fraser et al., 2008).

The evidence of population genetics studies, using selectively neutral markers, is that the benthivorous and the piscivorous morphs have diverged relatively recently, and in situ in Loch Rannoch, whereas the planktivorous morph diverged earlier from the other two and in allopatry (Verspoor et al., 2010; GarduñoPaz et al., 2012).

In this study, we examine this three-morph sympatric polymorphism of Arctic charr for variation in traits which are poorly studied and not fully understood, but which are likely to have a functional significance for salmonid fishes, namely gill and fin anatomy, and dentition. In this study, we specifically test one principal hypothesis:

(1) That the differences in functional phenotypic characteristics will be greater between the older than between the more recent morph divergences.

However, a number of testable subsidiary working hypotheses which relate foraging ecology to functional characteristics are also tested:

(2) That as a result of its active, pelagic life-style, the planktivorous morph will exhibit a more complex fin anatomy than the other two morphs.
(3) The planktivorous morph will exhibit longer and more closely spaced gill rakers than the other two forms as a functional response to feeding on the smallest size prey of the three forms.

(4) The planktivorous morph, likely the most mobile and thus with potentially the highest respiratory requirements, will have the largest gill cavity (to accommodate larger gills) of the three morphs.

(5) As it feeds on large prey, the piscivorous morph will have the largest buccal cavity of the three forms.

(6) Because it feeds on the most mobile prey that is difficult to subdue, the piscivorous morph will express more and larger teeth than the other two forms.

\section{Materials and methods}

Study system

Loch Rannoch is a recently glaciated freshwater lake in the Scottish Highlands $\left(56^{\circ} 41.3^{\prime} \mathrm{N} ; 004^{\circ} 17.7^{\prime} \mathrm{W}\right)$. It is at $203 \mathrm{~m}$ altitude, has a surface area of $17 \mathrm{~km}^{2}$ and a maximum depth of $134 \mathrm{~m}$ (Murray \& Pullar, 1910). Scotland was glaciated during the last glacial period, and thus the freshwater fish communities are relatively young, with the earliest invasions of emerging fresh waters likely around 12,000 years ago (Clark et al., 2012).

Charr from each of the three morphs $(N>30$ of each form) was collected from Loch Rannoch by benthic gill net in October 2010. Gill nets were set at known sites for each of the three morphs (Adams et al., 1998) in late afternoon, left overnight and collected the following morning. Fish were killed at the sampling site, cooled and transported to the Scottish Centre for Ecology and the Natural Environment, University of Glasgow for subsequent analysis. Because of the possibility of incomplete gill raker or fin ray ossification, only fish likely to be sexually mature ( $>130 \mathrm{~mm}$ fork length) were analysed. The body sizes of the three forms collected showed considerable overlap (benthivore fork length $206.3 \pm 47.2 \mathrm{~mm} \quad($ mean $\pm \mathrm{SD}$ ) range 130-309 $\mathrm{mm}$; planktivore $234.1 \pm 17.8 \mathrm{~mm}$, range $192-263$ 
$\mathrm{mm}$; piscivore $288.2 \pm 52.0 \mathrm{~mm}$, range 164 $373 \mathrm{~mm})$.

Fin rays

The dorsal, pelvic and pectoral fins of each fish were dissected and then stretched and pined to a polystyrene board and photographed on a scale with a digital SLR camera mounted to a fixed copy stand illuminated by a fixed blue filtered light. There was no evidence of rudimentary fin rays, so all bony fin rays were subsequently counted from photographs.

\section{Dentition}

For each fish, the mandible and the glossohyal bone (the "tongue") were dissected from the lower jaw of each fish and the maxillary bone, pre-maxillary bone and palatine bone from the upper jaw (see Jobling, 1995 for anatomical description). The component parts of the jaw were then dried, cleaned and photographed using a digital SLR camera on a fixed stand on an appropriate scale. All teeth were subsequently counted on each component jaw part. An estimate of morph-specific tooth size was obtained by determining the maximum tooth size (the longest) for each fish. Teeth were measured for length digitally from the photographs using ImageJ. Teeth were measured from the tooth base, at the insertion point, along the mid-line to the tooth tip (Pascau \& Pere, 2013). Where the tooth was curved, this was thus a curvilinear measurement. From these data, means of maximum tooth length for each bony structure were determined separately for each morph.

\section{Gill arch and rakers}

The first gill arch was dissected from the left side of the fish and cleaned in water. There was no evidence of rudimentary gill rakers in the fish in this study, and so all gill rakers were counted by eye. The length of each gill raker was defined as the distance from the insertion point to the tip of the raker. Following Magnason \& Heitz (1971), the spacing between gill rakers was defined as the space between adjacent gill raker at their base. These variables and the total gill arch length were measured using a calibrated eyepiece micrometre fitted to a dissection microscope and used at $\times 10$ magnification.
Buccal and gill cavity size

Buccal cavity size of each fish was determined following a silicone moulding technique described by Okuda et al. (2002). Silicone was injected into the mouth of a subset of the fish prior to removal of the gill arches (see below) which prevented silicone leaking into the gill cavity area. The mouth was then closed and excess silicone wiped away and the gill cavity checked for leakage. Once the silicone had set, the mould was removed through the mouth. The size of the mould was then determined by weight and then converted to volume from measures of volume and weight (of larger volumes of silicone than those resulting from the moulds). This methodology was found to have a higher level of precision than initial attempts to measure volume of relatively small moulds directly. A similar technique was used to determine gill cavity size. In this case, the mould was made after all gill arches had been removed, and the silicone was injected into the gill cavity area. Leakage into the buccal cavity was prevented by packing the buccal cavity with cotton tissue.

\section{Analysis}

All anatomical variables measured were tested for their relationship with fish size by regressing the variable on fish size (weight or fork length) of all groups pooled. Where a significant relationship with fish size was detected, regression residuals were derived as a size-independent measure of that variable (Reist, 1986; Adams et al., 2003; Adams \& Huntingford, 2004). Tooth length, gill raker number and spacing were all found to be correlated with fish size and thus size corrected before further analysis. Amongst morph differences were test for using an ANOVA assuming unequal variances. A Tukey HSD post hoc test was used to examine pairwise morph differences. All analysis was conducted in $\mathrm{R}(\mathrm{R}$ Development Core Team, 2013).

\section{Results}

Fin rays

The number of fin rays in the caudal fin did not differ significantly amongst the three morphs of Arctic 
charr from Loch Rannoch (Table 1). In contrast, the fin ray number was significantly different amongst morphs for each of the other three fins. The dorsal fin ray number was significantly different amongst morphs $\left(F_{2,97}=19.8 ; P<0.0001\right)$; post hoc testing showing that the number of fin rays was significantly higher in the planktivorous morph compared with the other two morphs, which did not differ significantly (Fig. 1A).

The pelvic fin ray number was also significantly different amongst morphs $\left(F_{2,97}=9.6 ; P<0.0001\right)$. The mean ray number of the piscivorous morph was significantly lower than the other two morphs, which did not differ significantly from each other in post hoc tests (Fig. 1B).

The pectoral fin ray number also varied significantly amongst morphs $\left(F_{2,97}=5.8 ; P<0.05\right)$. In post hoc tests, the mean ray number of the planktivorous morph was significantly higher than the other two morphs which did not differ significantly (Fig. 1C).

Table 1 For each of the three Arctic charr morphs from Loch Rannoch, the mean number of fin rays and teeth on component parts of the mouth, the mean length of the largest tooth and
Dentition

The number of teeth on the glossohyal, on the maxillary bones and the pre-maxillary bone did not differ significantly amongst morphs (Table 1 ). However, the mean number of teeth on the mandible was significantly higher in the planktivore than the other two morphs $\left(F_{2,87}=5.4 ; P<0.007\right)$ (Fig. 2A). Interestingly, there was evidence of considerably greater variation in mandible tooth number in the benthivorous and piscivorous morphs than in the planktivorous morph and four benthivorous individuals, and six piscivorous individuals had no discernible mandible teeth at all. In contrast, the mean number of teeth on the palatine bone was significantly higher in the piscivorous morph than the other two $\left(F_{2,77}=4.8 ; P<0.02\right)$ (Fig. $\left.2 \mathrm{~B}\right)$.

Although the number of teeth on the pre-maxillary bone did not differ amongst morphs (Table 1), the mean length of the teeth did, with the mean length of the longest tooth, corrected for fish length, being greater in the piscivorous morph than the other two forms

mean gill raker length, spacing and gill arch (both halves combined) length are given. In addition, the mean buccal cavity and the mean gill cavity volume are given

\begin{tabular}{|c|c|c|c|c|c|c|c|c|c|c|c|c|c|}
\hline & \multicolumn{2}{|c|}{ Planktivorous } & \multirow[t]{2}{*}{ Range } & \multirow[t]{2}{*}{$N$} & \multicolumn{2}{|c|}{ Benthivorous } & \multirow[t]{2}{*}{ Range } & \multirow[t]{2}{*}{$N$} & \multicolumn{2}{|c|}{ Piscivorous } & \multirow[t]{2}{*}{ Range } & \multirow[t]{2}{*}{$N$} & \multirow[t]{2}{*}{$P$} \\
\hline & Mean & SD & & & Mean & SD & & & Mean & SD & & & \\
\hline Caudal fin ray & 23.71 & 1.79 & $21-28$ & 31 & 23.89 & 1.75 & $21-27$ & 35 & 23.63 & 1.35 & $21-26$ & 35 & N.S. \\
\hline $\begin{array}{l}\text { Number of teeth on } \\
\text { glossohyal }\end{array}$ & 7.89 & 1.53 & $4-11$ & 27 & 8.08 & 1.55 & $7-11$ & 26 & 8.73 & 1.95 & $7-12$ & 26 & N.S. \\
\hline $\begin{array}{l}\text { Number of teeth on } \\
\text { maxillary bone }\end{array}$ & 25.71 & 4.26 & $7-16$ & 28 & 26.04 & 4.56 & $9-18$ & 23 & 27.52 & 3.58 & $9-18$ & 25 & N.S. \\
\hline $\begin{array}{l}\text { Number of teeth on pre- } \\
\text { maxillary bone }\end{array}$ & 10.93 & 2.2 & $7-17$ & 27 & 11.08 & 2.8 & $3-14$ & 25 & 10.46 & 1.82 & $8-18$ & 26 & N.S. \\
\hline $\begin{array}{l}\text { Pre-maxillary tooth length } \\
(\mathrm{mm})\end{array}$ & 0.085 & 0.024 & & 27 & 0.073 & 0.021 & & 26 & 0.146 & 0.045 & & 26 & $<0.02 *$ \\
\hline $\begin{array}{l}\text { Maxillary bone tooth } \\
\text { length }(\mathrm{mm})\end{array}$ & 0.071 & 0.019 & & 23 & 0.067 & 0.026 & & 20 & 0.13 & 0.036 & & 21 & $<0.01 *$ \\
\hline $\begin{array}{l}\text { Glossohyal teeth length } \\
(\mathrm{mm})\end{array}$ & 0.13 & 0.02 & & 25 & 0.13 & 0.03 & & 27 & 0.21 & 0.05 & & 25 & $<0.0001 *$ \\
\hline $\begin{array}{l}\text { Mandible tooth length } \\
(\mathrm{mm})\end{array}$ & 0.68 & 0.28 & & 28 & 0.75 & 0.27 & & 28 & 1.85 & 0.43 & & 26 & $<0.02$ \\
\hline Gill raker spacing $(\mathrm{mm})$ & 0.73 & 0.12 & & 27 & 0.73 & 0.2 & & 34 & 1.18 & 0.24 & & 27 & $<0.0002 *$ \\
\hline Gill raker length (mm) & 1.91 & 0.34 & & 27 & 1.05 & 0.31 & & 34 & 1.92 & 0.33 & & 27 & $<0.0001 *$ \\
\hline Gill arch length (mm) & 29.7 & 2.32 & & 27 & 27.0 & 7.26 & & 34 & 50.21 & 8.44 & & 27 & $<0.0001 *$ \\
\hline Bucal cavity volume (ml) & 0.66 & 0.34 & & 31 & 0.53 & 0.39 & & 35 & 2.01 & 1.04 & & 34 & $<0.0001 *$ \\
\hline
\end{tabular}

The probability of a between-morph difference in each variable is given

* Indicates that these variables were correlated with body size in these charr, and so the statistical testing was executed on sizecorrected residuals for these variables 


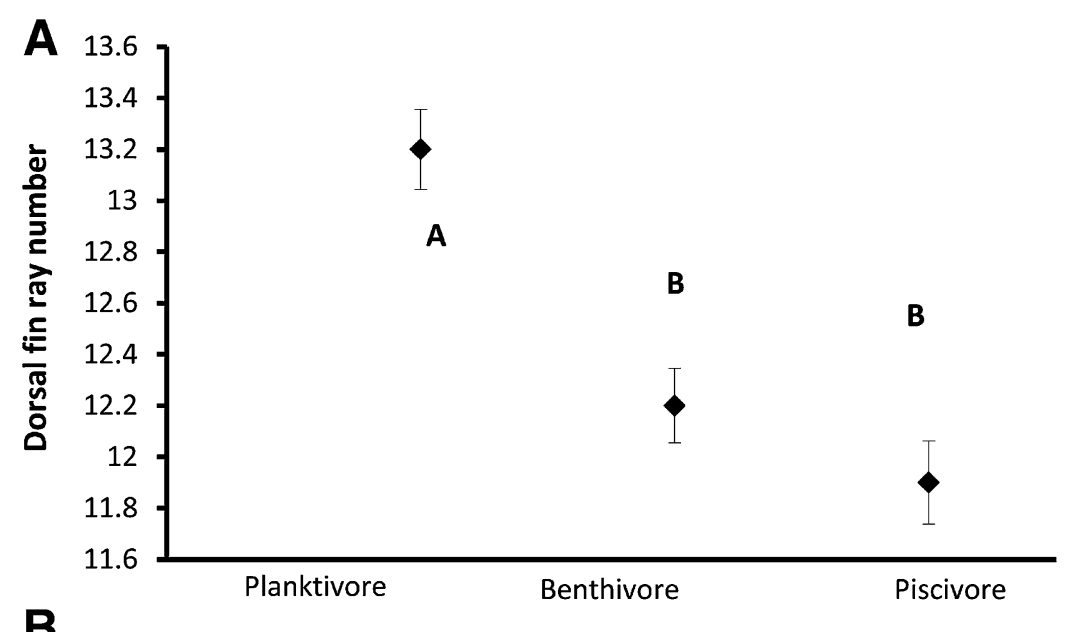

B
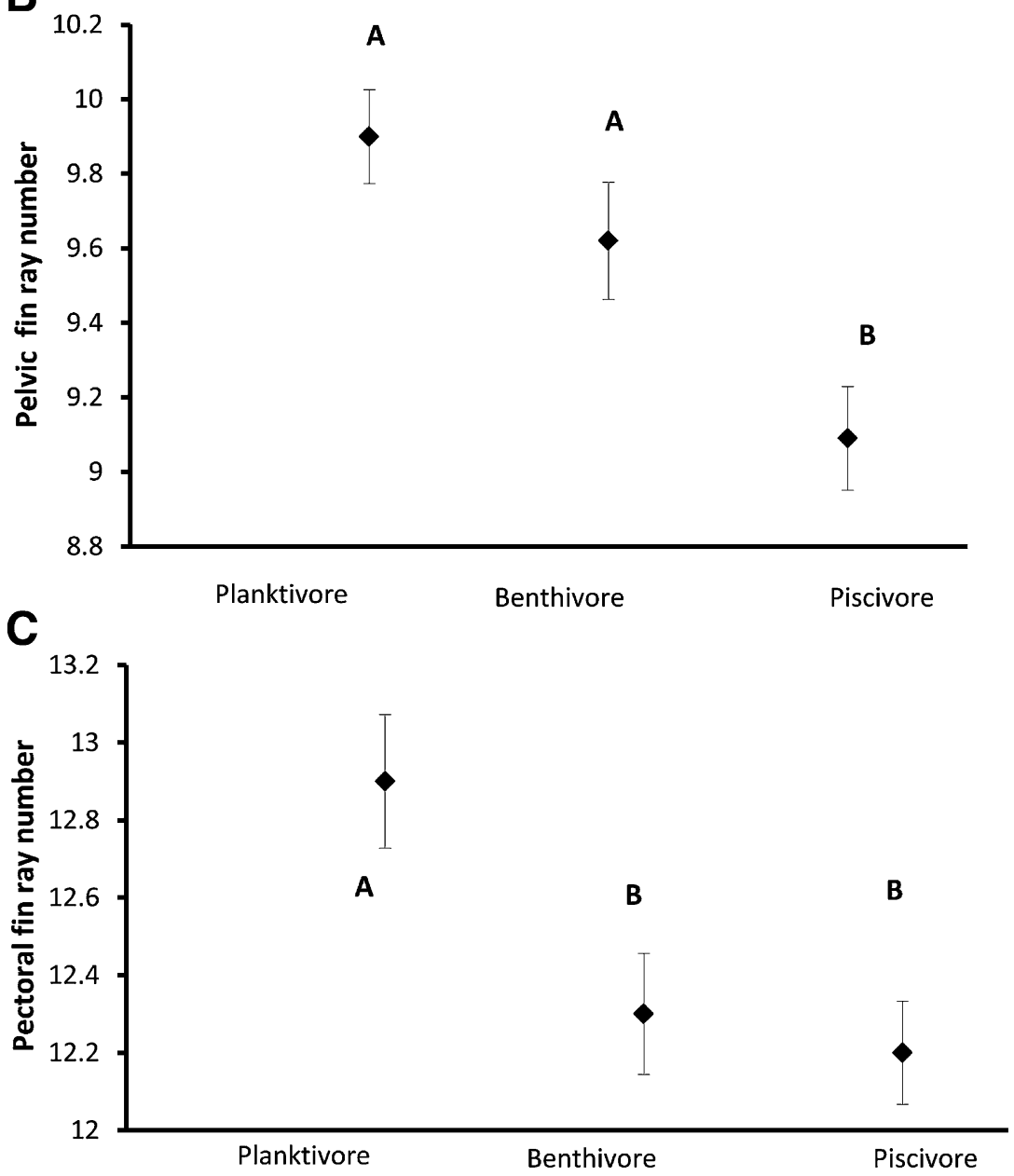

Fig. 1 The mean $( \pm S E)$ number of fin rays in each of the planktivorous, benthivorous and piscivorous morphs of Arctic charr from Loch Rannoch for A dorsal fins (range planktivore 12-14, benthivore 11-15, piscivore 9-13); B pelvic fins (range planktivore 9-11, benthivore 8-11, piscivore 8-11; C pectoral fins (range planktivore 11-14, benthivore 10-14, piscivore 11-13). Mismatching letters indicate a statistically significant difference $(<0.05)$ in pairwise post hoc testing 
$\left(F_{2,72}=4.28 ; P<0.02\right)$ (Fig. $3 \mathrm{~A}$; Table 1 shows the absolute measures of mean maximum tooth length). The maximum length of teeth on the maxillary bone differed significantly amongst morphs $\left(F_{2,61}=5.2 ; P<0.01\right)$. Maxillary teeth were shorter in the planktivorous morph than the piscivorous morph, but the two other morph pair comparisons did not differ significantly (Fig. 3B; uncorrected means in Table 1). The maximum tooth length on the glossohyal (corrected for fish body size) also differed very significantly amongst morphs $\left(F_{2,74}=32.1 ; P<0.0001 ;\right.$ Table 1$)$. The piscivore had a significantly longer maximum glossohyal tooth length and maximum mandible tooth length, once corrected for size than the other two morphs, which did not differ from each other (Fig. 3C, D; Table 1).

Gill arch and rakers

Gill raker number for the first gill arch was significantly different amongst morphs $\left(F_{2,85}=6.27\right.$;

Fig. 2 The mean $( \pm S E)$ number of teeth in of each of the planktivorous, benthivorous and piscivorous morphs of Arctic charr from Loch Rannoch on the mandible (A) and the palatine bone (B)

A
$P<0.001)$ with the piscivore having a significantly higher number of gill rakers than the planktivorous and benthivorous morphs which did not differ from each other (Fig. 4A). However, gill raker number was correlated with fish size $\left(F_{1,86}=4.59 ; P<0.04\right)$, and so residuals were derived from a regression of gill raker number on fish fork length. When fish size is taken into account, the difference in gill raker number amongst morphs is no longer significant, indicating that the larger number of gill rakers in piscivorous fish is a function of larger fish size in this group. Interestingly, the piscivorous morphs show considerably more variation in gill raker number than the other two morphs (Fig. 4A).

The mean spacing of gill rakers was correlated with fish size. The size-corrected residuals of gill raker spacing differed significantly amongst morphs $\left(F_{2,85}=9.7 ; P<0.0002\right)$ (Fig. 4B; Table 1$)$ with the piscivorous morph having gill rakers with a wider

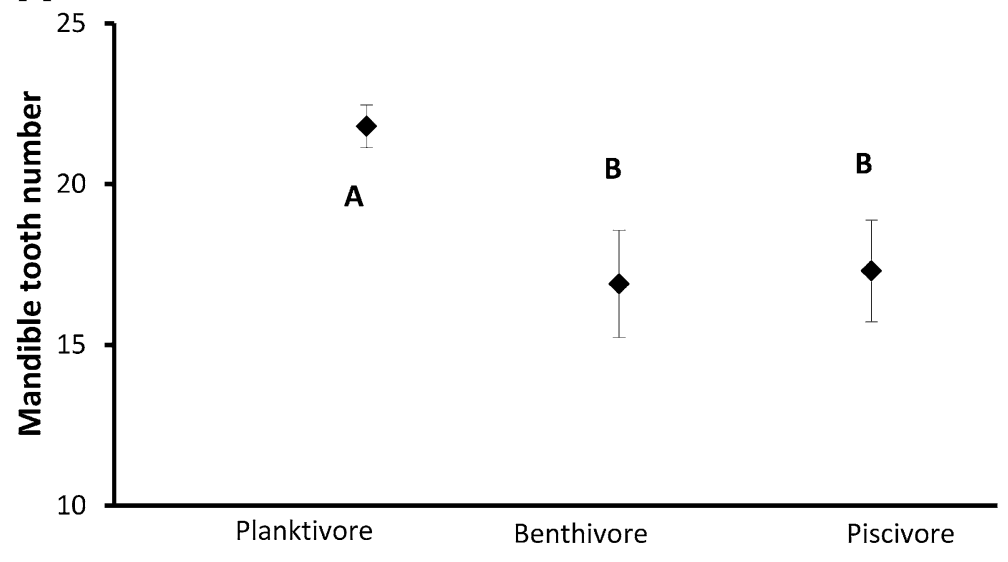

B

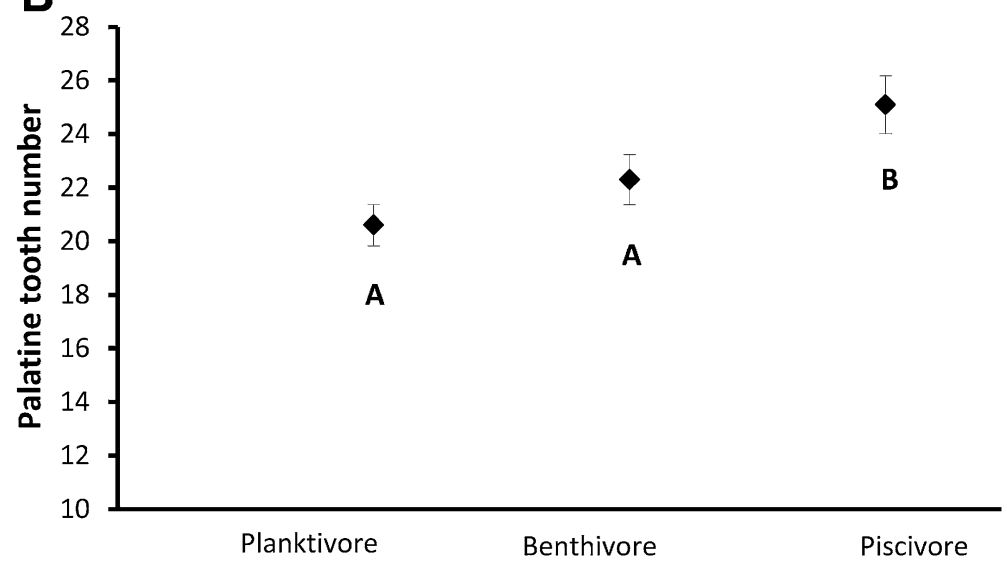




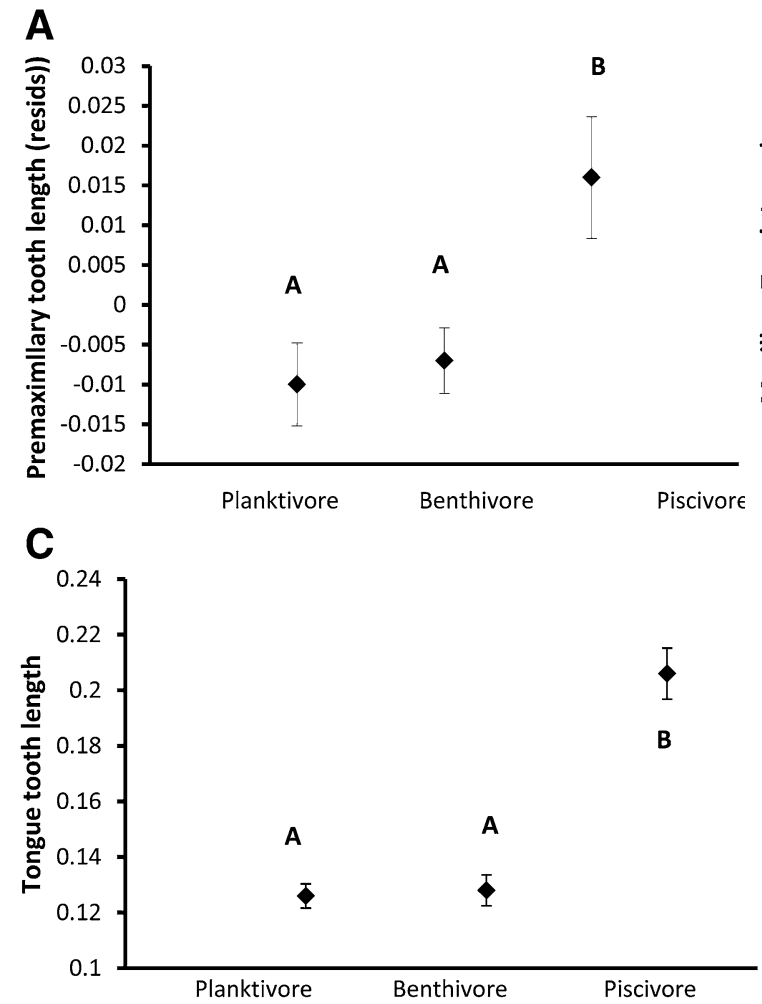

Fig. 3 The mean length of the longest tooth on the premaxillary bone (A), the maxillary bone $(\mathbf{B})$, the glossohyal (C) and the mandible (D) (corrected for fish size) for each of the planktivorous, benthivorous and piscivorous morphs of Arctic

spacing than that of other two, which did not differ between each other (Fig. 4B).

Mean gill raker length correlated with fish size. The size-corrected residuals of gill raker length varied significantly amongst morphs $\quad\left(F_{2,85}=37.1\right.$; $P<0.0001$ ) (Fig. 4C), with gill rakers in the benthivorous morph being significantly shorter than gill rakers in the piscivorous morph which had gill rakers significantly shorter than the planktivorous morph (Fig. 4C; Table 1).

Mean gill arch length, corrected for fish size, was statistically significantly different amongst morphs $\left(F_{2,85}=15.6 ; \quad P<0.0001\right)$ with the piscivorous morphs having a longer gill arch than the other two morphs which did not differ significantly between each other (Fig. 4D).

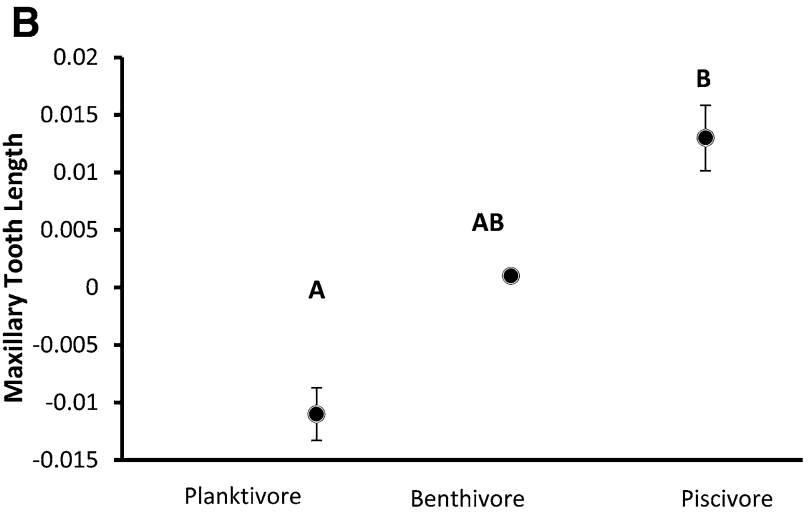

D

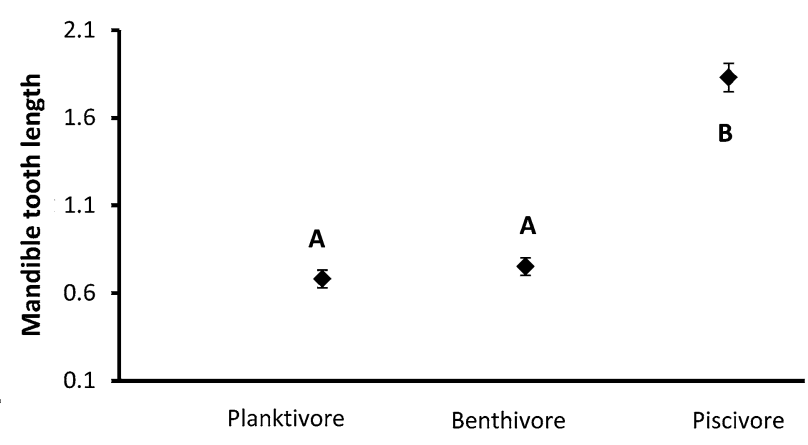

charr from Loch Rannoch. Mismatching letters indicate a statistically significant difference $(<0.05)$ in pairwise post hoc testing

Buccal and gill cavity size

The buccal cavity volume was correlated with fish size; the size-corrected residuals however showed significant differences amongst morphs $\left(F_{2,97}=59.3 ; \quad P<\right.$ 0.0001). The piscivorous morph had the largest buccal cavity volume compared with the other morphs (Fig. 5A); Table 1 gives the absolute measures of volume for each morph). The benthivorous morph had a marginally larger buccal cavity size than the planktivore, but this was not statistically significantly different (Fig. 5A). The gill cavity volume was also correlated with fish size; residuals derived from a gill cavity volume on fish size regression were analysed and showed clear differences amongst morphs $\quad\left(F_{2,97}=30.1\right.$; $P<0.0001)$. The gill cavity volume was smaller in the 

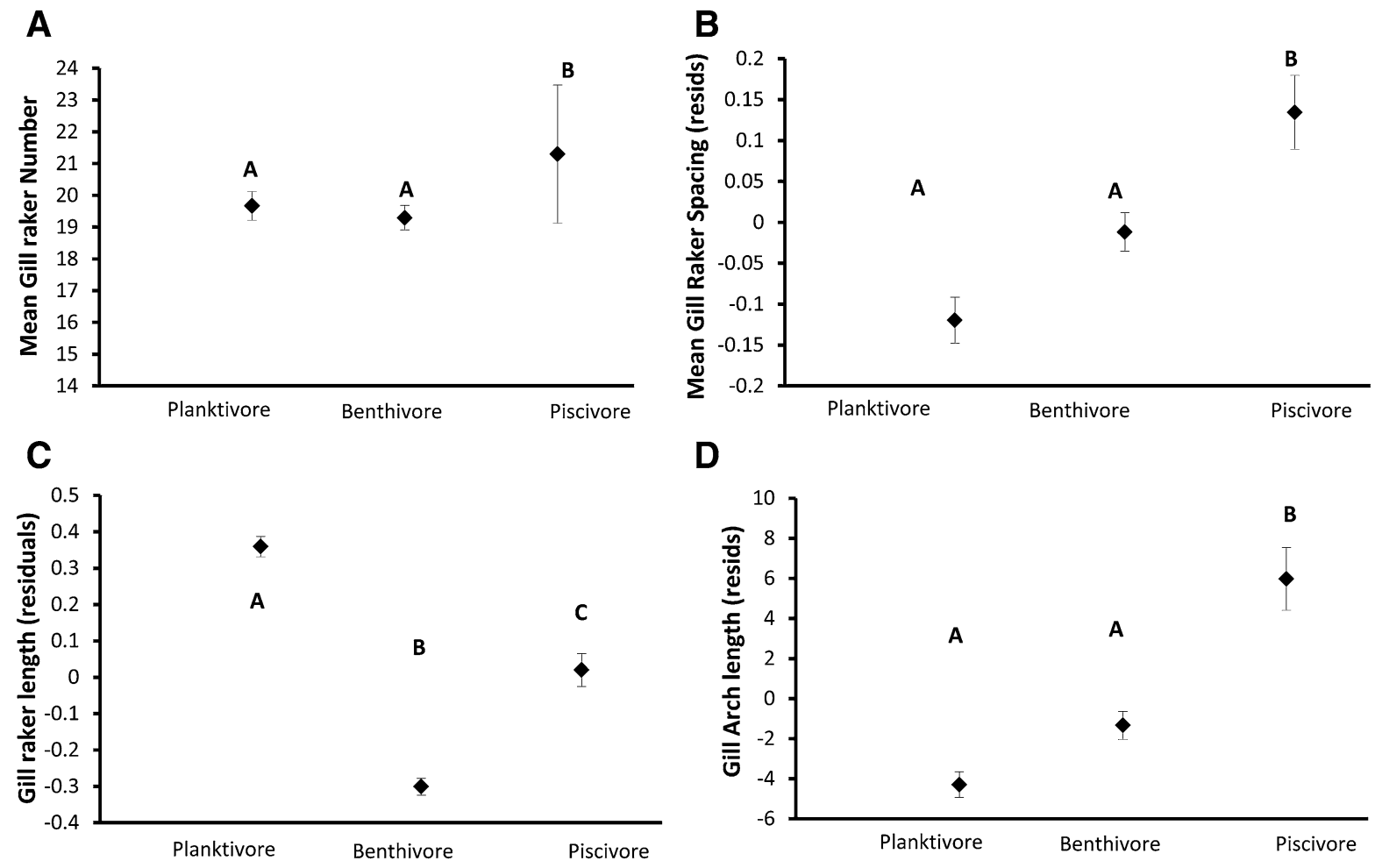

D

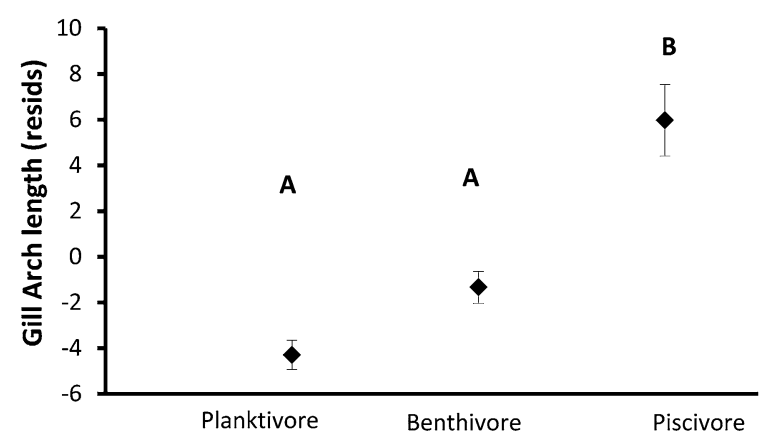

Fig. 4 The mean $( \pm \mathrm{SE})$ number of gill rakers on gill arch 1 (not corrected for fish size) (range planktivore 14-22, benthivore 12-21, piscivore 13-23) A their spacing (corrected for fish size), B length (corrected for fish size) $\mathbf{C}$ and gill arch length

planktivorous morph than in the other two morphs which did not differ between each other (Fig. 5B; Table 1).

\section{Discussion}

The pattern of foraging ecology specialisms and discrete morphology differences in the three morphs from Loch Rannoch (Adams et al., 1998) also clearly manifests as differences in other anatomical structures which are more difficult to quantify and thus less frequently reported but which have strong relevance to trophic functions. In general, the planktivore or the piscivore morphs tended to be the most divergent of the trophic traits reported here. There is strong evidence from neutral genetic markers that the planktivorous form diverged from the ancestral form of other two morphs before the postglacial invasion of (corrected for fish size) (D) for each of the planktivorous, benthivorous and piscivorous morphs of Arctic charr from Loch Rannoch. Mismatching letters indicate a statistically significant difference $(<0.05)$ in pairwise post hoc testing

Loch Rannoch by Arctic charr, and that the benthivorous and piscivorous morphs diverged in situ following invasion (Verspoor et al., 2010; Garduño-Paz et al., 2012). A logical expectation is that the degree of divergence in functional anatomy features might reflect the period of genetic divergence amongst groups (Hypothesis 1). This is not supported by this study. Of the 15 functional traits which showed significance between morph differences, the frequency of occurrence of a pairwise difference between the two more recently diverged genetic groups $(67 \%$; piscivore and benthivore) did not differ from that of the other two pairwise comparisons (60\% piscivore vs planktivore and benthivore vs planktivore) $\left(\left(\chi^{2}=0.28, P=0.6\right)\right.$. Thus, in this case, neutral population markers and putative selected traits do not seem to be directly coupled, and thus the principal hypothesis of this study (Hypothesis 1) is rejected. 
Fig. 5 The mean $( \pm S E)$ volume of the buccal cavity (corrected for fish size) (A) and the gill cavity size (corrected for fish size),

B for each of the planktivorous, benthivorous and piscivorous morphs of Arctic charr from Loch Rannoch. Mismatching letters indicate a statistically significant difference $(<0.05)$ in pairwise post hoc testing

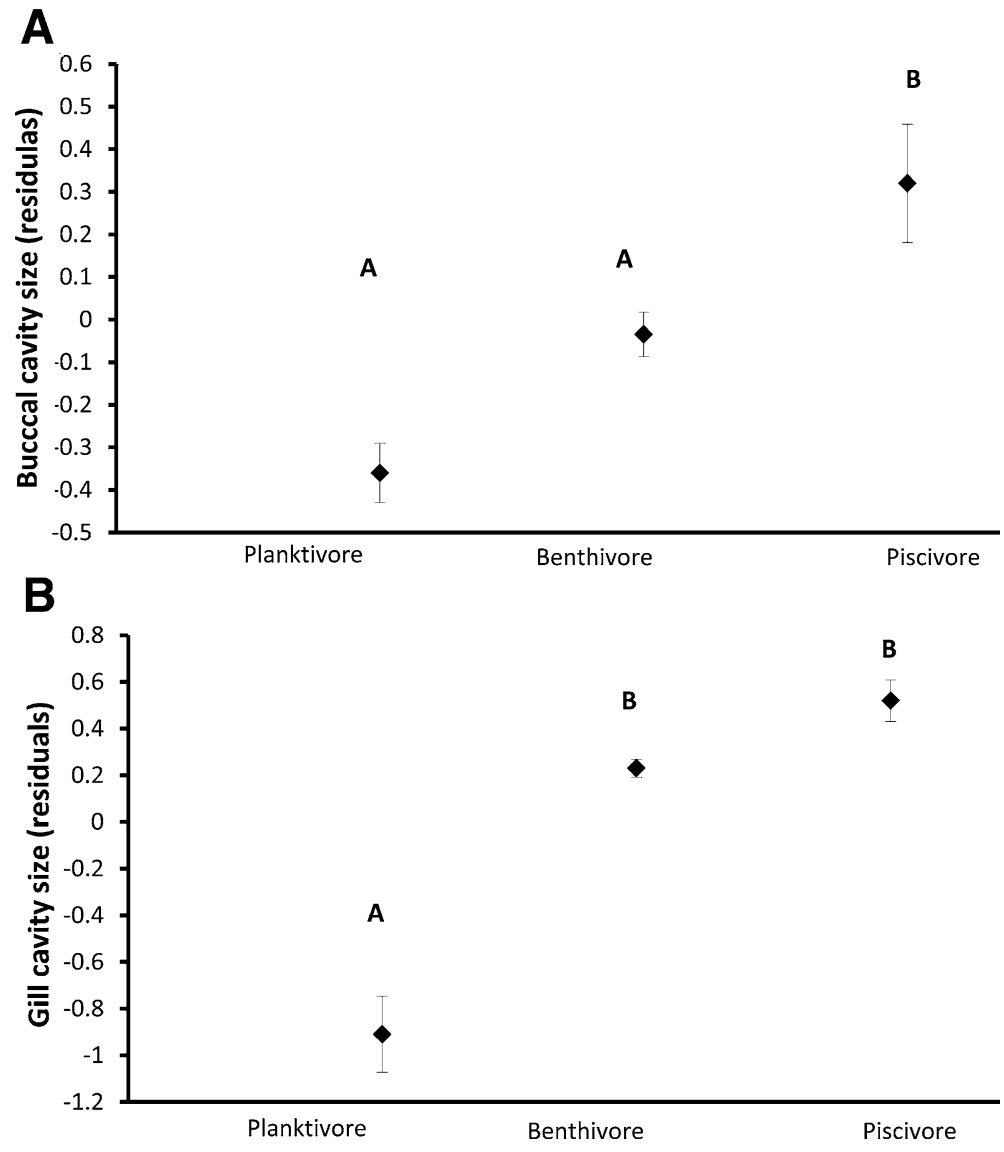

A
There were however a number of traits which showed logical trends which were in part predictable. In general, the greatest differences in fin ray number were seen in the planktivorous morph which had a significantly higher number of rays in the pectoral and dorsal fins than the other two morphs and in the pelvic fin than the piscivore. The planktivorous morph feeds on zooplankton in the limnetic zone; it is certainly more fusiform in body shape and is a more active swimmer than the other two morphs (Adams et al., 1998; Adams \& Huntingford, 2002b). Thus, it is a reasonable proposal that this form might show evidence of greater development of the bony structure of the fins associated with being a more active swimmer and speculatively with perhaps greater need for more precise swimming movements (Hypothesis 2).

In general, gill architecture is widely thought to reflect the prey sizes consumed by fish predators (O’Brian, 1987; Wooton, 1990). Amongst coregonids, which also frequently exhibit polymorphisms related to foraging specialisms, gill architecture often shows clear and discrete between-morph differences. Specifically, plankton-feeding specialists are often associated with longer and more closely spaced gill rakers (Amundsen et al., 2004; Kahilainen \& Ostbye, 2006; Kahilainen et al., 2011; Siwertsson et al., 2013). Thus, one logical and testable working hypothesis is that the specialist plankton-feeding morph will have longer and more closely spaced gill rakers than the other two morphs (Hypothesis 3). In this study, the gill arch structure did differ significantly across morphs. It was the piscivore however that had the highest number of gill rakers, but this effect was clearly driven by fish size and not directly by morph differences. Surprisingly, despite the clear differences in foraging specialisms (Adams et al., 1998), there was no difference in mean gill raker number between morphs. Despite this, the piscivorous morph had the longest gill arches with the greatest spacing between gill rakers of all three morphs (O'Brian, 1987). There may be a selective advantage of wider gill raker spacing in fish specialising of large prey such as fish. Furthermore, as 
might be predicted (Hypothesis 3), the planktivore had the longest gill rakers (independent of fish size), but the benthivore had the shortest and the piscivore intermediate length gill rakers (Langeland \& Nost, 1995). Thus Hypothesis 3 is only partly supported.

Contrary to the expectations (Hypothesis 4) that the morph with the presumptive highest activity levels, the planktivorous morph, was likely to have the largest gill cavity (to allow it to accommodate larger gills), the planktivorous morph had a smaller mean gill cavity size (once corrected for fish size) than the other two morphs. This is strongly suggestive of a difference in respiratory capacity amongst forms and a greater gill size in the benthivorous and piscivorous morphs. The functional driver for this is not clear, but it may be connected to the constant swimming required of planktivorous fish during feeding activity which may allow this morph to attain a high rate of gill perfusion, and thus although this was not tested directly, one possibility is that a smaller volume of gill cavity may meet the respiratory needs of this morph without the costs of a large gill structure.

In support of the Hypothesis 5, the buccal cavity of the piscivorous morph was larger than those of the other morphs, suggesting a functional significance related to the larger prey sizes consumed by piscivores compared with the planktivorous and benthivorous morphs. It is a logical premise that dentition may differ amongst the three foraging morphs. As the piscivorous morph feeds upon highly mobile prey that is difficult to catch and subdue, one expectation might be that the piscivorous morph might express more and longer teeth than the other morphs (Hypothesis 6). Tooth length (defined by the size of the longest tooth in each individual fish) was indeed longer in the piscivorous morph on the glossohyal and the pre-maxillary bone (although not longer than the benthivorous morph on the maxillary bone). This suggests stronger differential selection for tooth number and length in the piscivorous morph compared with the other two morphs. The planktivorous morph had a greater number of teeth on the mandible; the functional significance of this is unclear.

Taken together, the clear differences in a range of anatomical structures in fin and gill anatomy, and dentition have strong relevance to trophic functionality and the trophic performance of the respective morphs (Adams et al., 1998). This points to these traits being adaptive and responding to the differential selection environments, to which these three foraging specialists are exposed. This study does not allow us to determine if these trait expression differences are heritable or expressed through phenotypic plasticity. A high degree of heritability has however been shown in trophic morphology traits in Arctic charr from Loch Rannoch and in other morph pairs (Skulason et al., 1993; Adams \& Huntingford, 2002b, 2004; Klemetsen et al., 2002). Further experimental studies are needed to desegregate the mechanistic origin of the differences seen in fin and gill anatomy, and dentition.

Three morphs of Arctic charr living in sympatry that includes a piscivore are relatively rare. A system which includes a piscivorous morph however has recently been described from a sub-Arctic lake in northern Norway (Skoglund et al., 2015; Knudsen et al., 2016), and a piscivore is also well known from Thingvallavatn in Iceland (Jonsson \& Skulason, 2000). It has been suggested by Knudsen and coworkers (Knudsen et al., 2016) that the relative paucity of descriptions of piscivorous charr morphs indicates that very special conditions are required to promote the adaptations in trophic morphology and behaviour, allowing the emergence of fish foraging specialists. The pattern of genetic divergence between morphs (Verspoor et al., 2010; Garduño-Paz et al., 2012) appears that the specialised piscivorous morph has arisen locally (in situ), that Loch Rannoch has the conditions to enable the divergence, and continued maintenance, of a piscivorous charr as a discrete genetic group from the closely related benthivore and that its emergence has been driven by strong selection forces operating on trophic anatomy.

The conclusion of this study is that the functionally adaptive traits examined in this study are neither numerous nor more pronounced in the older divergences of sympatric Arctic charr morphs than in those which appeared more recently. Thus, between-morph divergences in the expression of adaptive foraging related traits are not simply linked to the period of divergence in the Arctic charr in Loch Rannoch and have arisen equally quickly in the recent (and in situ) divergence as they have in older ex situ divergences.

Acknowledgments This work would not have been possible without the continuing support of the Loch Rannoch Conservation Association, Richard Legate and Robert Benson. Derek Pretswell provided invaluable field support. 
Open Access This article is distributed under the terms of the Creative Commons Attribution 4.0 International License (http:// creativecommons.org/licenses/by/4.0/), which permits unrestricted use, distribution, and reproduction in any medium, provided you give appropriate credit to the original author(s) and the source, provide a link to the Creative Commons license, and indicate if changes were made.

\section{References}

Adams, C. E. \& F. A. Huntingford, 2004. Incipient speciation driven by phenotypic plasticity? Evidence from sympatric populations of Arctic charr. Biological Journal of the Linnean Society 81: 611-618.

Adams, C. \& F. Huntingford, 2002a. The functional significance of inherited differences in feeding morphology in a sympatric polymorphic population of Arctic charr. Evolutionary Ecology 16: 15-25.

Adams, C. \& F. Huntingford, 2002b. Inherited differences in head allometry in polymorphic charr from Loch Rannoch, Scotland. Journal of Fish Biology 60: 515-520.

Adams, C. E., D. Fraser, F. A. Huntingford, R. B. Greer, C. M. Askew \& A. F. Walker, 1998. Trophic polymorphism amongst Arctic charr from Loch Rannoch, Scotland. Journal of Fish Biology 52: 1259-1271.

Adams, C. E., C. Woltering \& G. Alexander, 2003. Epigenetic regulation of trophic morphology through feeding behaviour in Arctic charr, Salvelinus alpinus. Biological Journal of the Linnean Society 78: 43-49.

Adams, C. E., A. J. Wilson \& M. M. Ferguson, 2008. Parallel divergence of sympatric genetic and body size forms of Arctic charr, Salvelinus alpinus, from two Scottish lakes. Biological Journal of the Linnean Society 95: 748-757.

Alekseyev, S. S., V. P. Samusenok, A. N. Matveev \& M. Yu, 2002. Diversification, sympatric speciation, and trophic polymorphism of Arctic charr, Salvelinus alpinus complex, in Transbaikalia. Environmental Biology of Fishes 64: 97-114.

Amundsen, P., T. Bøhn \& G. H. Våga, 2004. Gill raker morphology and feeding ecology of two sympatric morphs of European whitefish (Coregonus lavaretus). Annales Zoologici Fennici 41: 291-300.

Burress, E. D., 2015. Cichlid fishes as models of ecological diversification: patterns, mechanisms, and consequences. Hyrdobiologia 748: 7-27.

Bush, V. \& C. E. Adams, 2007. Using phenotypic variation to determine conservation value: application of a novel approach to Arctic charr. Ecology of Freshwater Fish 16: 29-33.

Clark, C. D., A. L. C. Hughes, S. L. Greenwood, C. Jordan \& H. P. Sejrup, 2012. Pattern and timing of retreat of the last British-Irish Ice Sheet. Quaternary Science Reviews 44: 112-146.

Danzmann, R. G., M. M. Ferguson, S. Skulason, S. S. Snorrason \& D. L. G. Noakes, 1991. Mitochondrial-DNA diversity among 4 sympatric morphs of Arctic charr, Salvelinusalpinus L, from Thingvallavatn, Iceland. Journal of Fish Biology 39: 649-659.
Defaveri, J., T. Shikao, S. Yukinori \& J. Merla, 2013. High degree of genetic differentiation in marine three-spined sticklebacks (Gasterosteus aculeatus). Molecular Ecology 22: 4811-4828.

Dorucu, M., C. E. Adams, F. A. Huntingford \& D. W. T. Crompton, 1995. How fish-helminth associations arise: an example from Arctic charr in Loch Rannoch. Journal of Fish Biology 47: 1038-1043.

Ferguson, A., 1989. Genetic differences among brown trout, Salmo trutta, stocks and their importance for the conservation and management of the species. Freshwater Biology 21: $35-46$.

Fraser, D., C. E. Adams \& F. A. Huntingford, 1998. Trophc polymorphsm among Arctic charr Salvelinus alpinus L., from Loch Ericht. Scotland. Ecology of Freshwater Fish 7: 184-191.

Fraser, D., F. A. Huntingford \& C. E. Adams, 2008. Foraging specialisms, prey size and life-history patterns: a test of predictions using sympatric polymorphic Arctic charr (Salvelinus alpinus). Ecology of Freshwater Fish 17: 1-9.

Frost, W. E., 1965. Breeding Habits of Windermere Charr, Salvelinus willughbii (Gunther), and their Bearing on Speciation of these Fish. Proceedings of the Royal Society B: Biological Sciences 163: 232-284.

Gagnaire, P.-A., S. A. Pavey, E. Normandeau \& L. Bernatchez, 2013. The genetic architecture of reproductive isolation during speciation-with-gene-flow in lake whitefish species pairs assessed by RAD sequencing. Evolution 67: 2483-2497.

Garant, D., S. Forde \& A. Hendry, 2007. The multifarious effects of dispersal and gene flow on contemporary adaptation. Functional Ecology 21: 434-443.

Garduño-Paz, M. V., C. E. Adams, E. Verspoor, D. Knox \& C. Harrod, 2012. Convergent evolutionary processes driven by foraging opportunity in two sympatric morph pairs of Arctic charr with contrasting post-glacial origins. Biological Journal of the Linnean Society 106: 794-806.

Gerking, S. D., 1994. Feeding Ecology of Fishes. Academic Press, San Diego.

Gislason, D., M. Ferguson, S. Skulason \& S. S. Snorrason, 1999. Rapid and coupled phenotypic and genetic divergence in Icelandic Arctic char (Salvelinus alpinus). Canadian Journal of Fisheries and Aquatic Sciences 56: 2229-2234.

Gowell, C. P., T. P. Quinn \& E. B. Taylor, 2012. Coexistence and origin of trophic ecotypes of pygmy whitefish, Prosopium coulterii, in a south-western Alaskan lake. Journal of Evolutionary Biology 25: 2432-2448.

Hendry, A. P., D. I. Bolnick, D. Berner \& C. L. Peichel, 2009. Along the speciation continuum in sticklebacks. Journal of Fish Biology 75: 2000-2036.

Ishikawa, A., N. Takeuchi, M. Kusakabe, M. Kume, S. Mori, H. Takahashi \& J. Kitano, 2013. Speciation in ninespine stickleback: reproductive isolation and phenotypic divergence among cryptic species of Japanese ninespine stickleback. Journal of Evolutionary Biology 26: 1417-1430.

Jobling, M., 1995. Environmental Biology of Fishes. Chapman \& Hall, London.

Jonsson, B. \& N. Jonsson, 2001. Polymorphism and speciation in Arctic charr. Journal of Fish Biology 58: 605-638.

Jonsson, B. \& S. Skulason, 2000. Polymorphic segregation in Arctic charr Salvelinus alpinus (L.) from Vatnshlidarvatn, 
a shallow Icelandic lake. Biological Journal of the Linnean Society 69: 55-74.

Kahilainen, K. \& K. Ostbye, 2006. Morphological differentiation and resource polymorphism in three sympatric whitefish Coregonus lavaretus (L.) forms in a subarctic lake. Journal of Fish Biology 68: 63-79.

Kahilainen, K. K., A. Siwertsson, K. Ø. Gjelland, R. Knudsen, T. Bohn \& P.-A. Amundsen, 2011. The role of gill raker number variability in adaptive radiation of coregonid fish. Evolutionary Ecology 25: 573-588.

Kang, J.-H., J.-Y. Park, E.-M. Kim \& H.-S. Ko, 2013. Population genetic analysis and origin discrimination of snow crab (Chionoecetes opilio) using microsatellite markers. Molecular Biology Reports 40: 5563-5571.

Klemetsen, A., 2010. The charr problem revisited: exceptional phenotypic plasticity promotes ecological speciation in postglacial lakes. Freshwater Reviews 3: 49-74.

Klemetsen, A., J. Elliot, R. Knudsen \& P. Sorensen, 2002. Evidence for genetic differences in the offspring of two sympatric morphs of Arctic charr. Journal of Fish Biology 60: 933-950.

Klemetsen, A., P.-A. Amundsen, J. B. Dempson, B. Jonsson, N. Jonsson, M. F. O'Connell \& E. Mortensen, 2003. Atlantic salmon Salmo salar L., brown trout Salmo trutta L. and Arctic charr Salvelinus alpinus (L.): a review of aspects of their life histories. Ecology of Freshwater Fish 12: 1-59.

Knudsen, R., P. Amundsen, R. Primicerio, A. Klemetsen \& P. Sørensen, 2007. Contrasting niche-based variation in trophic morphology within Arctic charr populations. Evolutionary Ecology Research 9: 1005-1021.

Knudsen, R., K. Ø. Gjelland, A. P. Eloranta, B. Hayden, A. Siwertsson, P.-A. Amundsen \& A. Klemetsen, 2016. A specialised cannibalistic Arctic charr morph in the piscivore guild of a subarctic lake. Hydrobiologia. doi:10.1007/ s10750-015-2601-x.

Langeland, A. \& T. Nost, 1995. Gill raker structure and selective predation on zooplankton by particulate feeding fish. Journal of Fish Biology 47: 719-732.

Lavin, P. \& J. McPhail, 1986. Adaptive divergence of trophic phenotype among freshwater populations of the threespine stickleback (Gasterosteus aculeatus). Canadian Journal of Fisheries and Aquatic Sciences 43: 2455-2463.

Magnason, J. \& J. Heitz, 1971. Gill raker apparatus and food selectivity among mackerels, tunas and dolphins. Fish Bulleten 69: 361-370.

Mikheev, V. C., C. E. Adams, F. A. Huntingford \& J. E. Thorpe, 1996. Behavioural responses of benthic and pelagic Arctic charr to substrate heterogeneity. Journal of Fish Biology 49: 494-500.

Muir, A. M., M. J. Hansen, C. R. Bronte \& C. C. Krueger, 2015. If Arctic charr Salvelinus alpinus is "the most diverse vertebrate", what is the lake charr Salvelinus namaycush? Fish and Fisheries 10: 1111.

Murray, J. \& L. Pullar, 1910. A bathymetrical survey of Scottish lochs. Challanger Office, Edinburgh.

O'Brian, W., 1987. Planktivory in freshwater fish: thrust and parry in pelagia. In Kerfoot, W. \& A. Sih (eds), Predation: Direct and Indirect Effects on Aquatic Communities. University Press of New England, New Hampshire: 3-6.

Okuda, N., M. Miyazaki \& Y. Yanagisawa, 2002. Sexual difference in buccal morphology of the paternal mouthbrooding cardinalfish Apogon doederleini. Zoological Science 19: 801-807.

Pascau, J. \& J. Pere, 2013. Image Processing with ImageJ. Packt Publishing, Birmingham.

R Development Core Team, 2013. R: A Language and Environment for Statistical Computing. R Foundation for Statistical Computing, Vienna.

Reist, J., 1986. An empirical evaluation of several univariate methods that adjust for size variation in morphometric data. Canadian Journal of Zoology 63: 1429-1439.

Siwertsson, A., R. Knudsen, C. E. Adams, K. Præbel \& P.-A. Amundsen, 2013. Parallel and non-parallel morphological divergence among foraging specialists in European whitefish (Coregonus lavaretus). Ecology and Evolution 3: 1590-1602.

Skoglund, S., A. Siwertsson, P. Amundsen \& R. Knudsen, 2015. Morphological divergence between three Arctic charr morphs - the significance of the deep-water environment. Ecology and Evolution 5: 3114-3129.

Skulason, S., S. S. Snorrason, D. Ota \& D. L. G. Noakes, 1993. Genetically based differences in foraging behavior among sympatric morphs of Arctic charr (Pisces, Salmonidae). Animal Behaviour 45: 1179-1192.

Skulason, S., S. Snorrason \& B. Jonsson, 1999. Sympatric morphs populations and speciation in freshwater fish with emphasis on arctic charr. In Magurran, A. \& R. May (eds), Evolution of Biological Diversity. Oxford University Press, Oxford: 70-92.

Svanbäck, R. \& P. Eklöv, 2004. Morphology in perch affects habitat specific feeding. Functional Ecology 18: 503-510.

Svanbäck, R. \& L. Persson, 2004. Individual diet specialization, niche width and population dynamics: implications for trophic polymorphisms. Journal of Animal Ecology 73: 973-982.

Swislocka, M., M. Czajkowska, N. Duda, J. Danylow, E. Owadowska-Cornil \& M. Ratkiewicz, 2013. Complex patterns of population genetic structure of moose, Alces alces, after recent spatial expansion in Poland revealed by sex-linked markers. Acta Theriologica 58: 367-378.

Taft, N. K. \& B. N. Taft, 2012. Functional implications of morphological specializations among the pectoral fin rays of the benthic longhorn sculpin. Journal of Experimental Biology 215: 2703-2710.

Verspoor, E., J. Beardmore, S. Consuegra, C. Garcia de Leaniz, A. Mahkrov, T. Paaver, J. Sanchez, O. Skaala, S. Titov \& T. Cross, 2005. Population structure in the Atlantic salmon: insights from 40 years of research into genetic protein variation. Journal of Fish Biology 67: 3-54.

Verspoor, E., D. Knox, R. Greer \& J. Hammar, 2010. Mitochondrial DNA variation in Arctic charr (Salvelinus alpinus (L.)) morphs from Loch Rannoch, Scotland: evidence for allopatric and peripatric divergence. Hydrobiologia 650: 117-131.

Woods, P. J., S. Skulason, S. S. Snorrason, B. K. Kristjansson, H. J. Malmquist \& T. P. Quinn, 2012. Intraspecific diversity in Arctic charr, Salvelinus alpinus, in Iceland: II. Which environmental factors influence resource polymorphism in lakes? Evolutionary Ecology Research 14: 993-1013.

Wooton, R., 1990. The Ecology of Teleost Fishes. Springer, London. 